\title{
Epigenetic Control of Sociality through DNA Methylation
}

\author{
Ipsita Samal* \\ Department of Entomology, I.A.R.I, New Delhi, India \\ *Corresponding author
}

\section{A B S T R A C T}

The success of social insects is governed by remarkable levels of phenotypic plasticity displayed by colony members which is mediated by epigenetic inheritance. Waddington originally defined epigenetics as the study of the mechanisms that led to the development of a particular phenotype from a given genotype. Social insects have been primary model systems used for understanding the importance of insect DNA methylation. Epigenetic states are initiated by some type of environmental stimulus. DNA methylation is recognized as an important chromatin modification providing structural integrity and proper regulation of the genome for many species. In animals DNA methylation typically occurs at CG sites, established de novo by DNA methyl transferase 3 (DNMT3), and maintained by the methyl

\section{Keywords}

Phenotypic plasticity, Epigenetics, DNA methylation, Eusocial, Genomic data

\section{Article Info}

Accepted:

20 September 2018 Available Online: 10 October 2018 transferase DNMT1. The sequencing of the honeybee genome led to the discovery of a fully functional methylation system and caste determination has been found to involve epigenetic regulation. Furthermore, Cytosine methylation was reported to play a key role in the learning and memory processes of honey bees. Moreover, dynactin p62 is more highly methylated in worker honeybees than in queens, and queen larvae expressed higher dynactin p62. Zootermopsis nevadensis nuttingi (Termopsidae) also exhibits a high level of DNA methylation, which is helpful in regulating phenotypic plasticity, as for other eusocial Hymenoptera. Fertile queens and sterile workers are alternative forms of the adult female honeybee that develop from genetically identical larvae following differential feeding with royal jelly. Thus nutritional factors have been reported to control the reproductive behaviour in social insects. Nutritional input, acts as an agent of epigenetic modifications leads to different developmental fates, with massive implications for reproductive and behavioral status. In Apis mellifera DNA methylation is a key component of an epigenetic network controlling a most important aspect of eusociality, the reproductive division of labor. Social insects in particular are exceptionally promising models in DNA methylation studies because of the presence of outstanding phenotypic plasticity and ample potential for genomic imprinting. This concern of DNA methylation will grow with the continued exploration of insect genomic data and the continued sequencing of insect DNA methylomes.

\section{Introduction}

\section{What is epigenetics?}

"Epi" means above and "genetics" means the genetic composition of insects, thus epigenetics means some factors other than genes that govern the phenotype of an organism.

This phenomenon is termed as epigenetics. Basically phenotype of an organism is 
governed by genotype $(\mathrm{G})$, environment $(\mathrm{E})$ and genotype and environment $\left(\begin{array}{lll}G & X & E\end{array}\right)$ interactions.

In this regard the sociality in insects is a result of epigenetic behavior, because this sociality consists of following four criteria such as (Wilson, 1971):

Common nest site

Cooperative brood care

Reproductive caste

Generation overlap

For studying the epigenetic behavior in insects Drosophila melanogaster has not been taken as the model insects, inspite of this various social insects has been taken into consideration in this aspect. Mostly because the methylation status in insects shows a bimodal distribution because some genes are hyper methylated where as some other genes are reported to be hypo methylated, which leads to developmental plasticity in social insects i.e. evolution of caste system, polyphenism, division of labour etc.

As observed from the above diagram the $D$. melanogaster shows an unimodal distribution, whereas the honey bee Apis mellifera, Acyrthosiphon pisum and Nasonia vitripennis were reported to exhibit bimodal distribution, indicating that some genes governing various phenotypic character are hypomethylated whereas some other genes are hypermethylated. Thus the forementioned insects were observed with various levels of phenotypic plasticity in response to various environmental factors. Apis mellifera, the eusocial Europen honey bee has been reported with different morphological forms induced by different levels of diet, such as if the 3 day old larva of honey bee is fed with royal jelly, then the queen will be produced. Furthermore if the 3 days old female larva of honey bee is reared with bee bread i.e. pollen and honey, then it will become an worker. Similarly in pea aphid, different winged and wingless forms are also reported to be associated with the hyper and hypomethylation of genes. If Nasonia vitripennis is taken into consideration, the short and long photo periods are reported to be the environmental factor that are regulating epigenetic behavior in this hymenopteran insect.

\section{What is DNA methylation?}

As mentioned earlier, the bimodal distribution of DNA methylation leads to development of different phenotypes. CG (Cytosine and Guanine) rich regions otherwise known as $\mathrm{CG}$ islands are the most crucial site for DNA methylation, because as the methyl group is attached to the cytosine nucleotide, the cytosine is being converted to Thymine, thus the entire base sequence will be changed.

DNA methylation is the result of activity of 3 different types of enzymes such as DNA methyl transferase 1, 2 and 3 (DNMTs). Among these DNMT 3 causes de novo DNA methylation, whereas DNMT 1 is the maintenance methyl transferase. The honey bee genome possesses a complete set of DNMTs, similar to $N$. vitripennis, the solitary parasitoid jewel wasp.

The full complement of DNMTs is found in honey bees, wasps and in human whereas the DNMT 3 is reported to be lost in beetles and silkworms, whereas, DNMT 1 and 3 are lost in Dipteran flies. Furthermore, all type of DNMTs are reported to be absent in nematodes. According to Glastard et al., (2013) the full complement of DNMTs are found in hymenopteran such as $N$. vitripennis, Acyrthosiphon pisum, Apis mellifera and Solenopsis invicta. According to Maleszka, 2012 the different DNMTs and their functional status throughout the arthropods has been confirmed. 
When the ds RNA is introduced in worker larva for silencing DNMT 3, the worker larva has been emerged as a queen, as described from the figure, from Miklos and Maleszka (2000).

\section{What is DNA methylation and its role in epigenetics}

The phenotype of an organism was governed by the genotype $(\mathrm{G})$, environment $(\mathrm{E})$ and genotype and environment $\left(\mathrm{G}^{*} \mathrm{E}\right)$ interactions. Apart from genotypes, the environmental factors act as the determining factor for the expression of phenotype.

The ecological adaptivity of insects are greatly attributed to their phenotypic plasticity. This epigenetic factor regulates the morphological and behavior criteria of an organism by the following 3 ways:

Methylation in DNA

Modification of histone protein

Activity of non-coding RNA

The diverse functionality of an eusocial class is attributed to the division of labour and differentiation of sex specific works.

For example, in the well-developed social insects, the queen and king are regarded as reproductive castes, whereas the workers and soldiers are involved in foraging and defense related activities (Wilson, 1971). The phenotypic plasticity in insects is a result of extreme level of differences in their morphology and physiology.

The different caste system in social insects is mainly triggered by diverse environmental cues, in the developing organisms, which further respond differentially to the environmental stimuli, by producing diverse phenotypes through the expression of diverse genes.

\section{What is epigenetic inheritance?}

Waddington (1942) describes epigenetics as the whole complex of developmental process, furthermore, this definition was modified by Nanney (1958) by concluding that the cellular phenotype was not entirely determined by the composition of genetic material i.e. DNA in the cell, rather some epigenetic systems determine the genetic potentialities of an organism. The epigenetic inheritance may be of 2 types i.e. intragenerational and intergenerational which occurs within generation and both generations respectively (Bossdorf et al., 2008; Richards, 2006).

Epigenetics basically starts with some environmental input, that will lead to different phenotypic output by modifying the existing genotypes. DNA methylation affects the gene function of an insect. Epigenetic modification can be passed to next or within generations by the modifications in DNA associated histone proteins. The third way of epigenetic modification is by the interaction with noncoding RNAs, this can alter cellular functions.

DNA methylation primarily occurs in Cytosine bases observed next to Guanine bases (i.e. 5- methyl cytosine in $\mathrm{CpG}$ dinucleotides). The principal enzyme involved in the process of DNA methylation are DNA methyl transferase (DNMTs) which includes DNMT 1, DNMT 2 and DNMT 3, out of which, DNMT 3 is reported to cause de novo methylation, whereas DNMT 1 is also known as maintenance methyl transferase (Lan et al., 2010: Law and Jacobson, 2010). The European honey bee has been taken as the model insect foe the study of epigenetic effects induced by DNA methylation.

In the study for DNA methylation, the queen model for genetic study, Drosophila melanogaster, has not been considered. According to Glastard et al., (2015), the 
bimodal peak is observed by the insects which are regulated by epigenetic modification through DNA methylation, indicating that some genes are methylated and others are unmethylated. The $\mathrm{CpG}$ o/e was considered as a measure of the functional DNA methylation, as the Cytosine has been methylated and converted to Thiamine, the $\mathrm{CpG}$ o/e was less for the insects in which DNA methylation occurs, and the respective ratio was higher in non-methylated insects.

The figure from Glastard et al., (2013) indicates the full complement of DNMTs is found in Hymenopterans only. But to some extent DNA methylation occurs in locust (nearly $8 \%$ ) in contrast to less than $1 \%$ in honey bee. Mostly the DNA methylation occurs in the genomic region, including exons and introns (Glastard et al., 2014).

As indicated by the following diagram, in Isopteran insects, the DNA methylation mostly occurs in the exonic regions, whereas, in hymenopteran social insects the DNA methylation occurs in intron regions specifically.

\section{Phenotypic plasticity}

From Pigliucci (2001), 4 different hypothesis has been proposed which indicate the epigenetic factors regulate the development of phenotypes from the same genotype, thus there are 3 factors regulate the development of phenotypes i.e. genotypes, environment and genotype and environment interactions.

Phenotypic plasticity may be defined as "the extent to which the environment modifies the phenotype". Among those fore mentioned 4 hypothesis, the fourth one is the most realistic one, which indicate the genotypeenvironment interaction as the epigenetic control mechanism in determining the diverse phenotype.
The phenotypic plasticity can be best explained by the typical eusocial model insect, the European honey bee, Apis mellifera. The DNA methylation in insects can be broadly divided into 3 types (Weiner and Toth, 2012):

Some genes remain unmethylated

Some genes are reported to be consistently methylated

Some genes are differentially methylated

Thus the honey bee first instar larva if provided with royal jelly, after 3 days of development, it will be destined to produce, the reproductive queen, whereas, if the 3 day old larva is fed with bee bread (pollen and nectar) the non- reproductive worker phenotype is being produced.

Even though, both the worker and queen larva have same genotype, the diet which is provided to the larva (both the royal jelly and bee bread) acts as the epigenetic modifier of the caste. Furthermore some genes are constitutively methylated, and some other are differentially methylated in worker and queen honey bee.

Consistent methylation represents some genes that are reported to be methylated throughout the insect taxa, which are otherwise the conserved pattern of DNA methylation. But differential methylation is reported to be involved in caste determination, division of labour.

\section{Signalling pathways in honey bee caste development}

As mentioned earlier, the DNA methylation involves 3 types of DNMTs, out of which DNMT 1 otherwise known as maintenance methyl transferase and DNMT 3 is also known as denovo methyl transferase. 

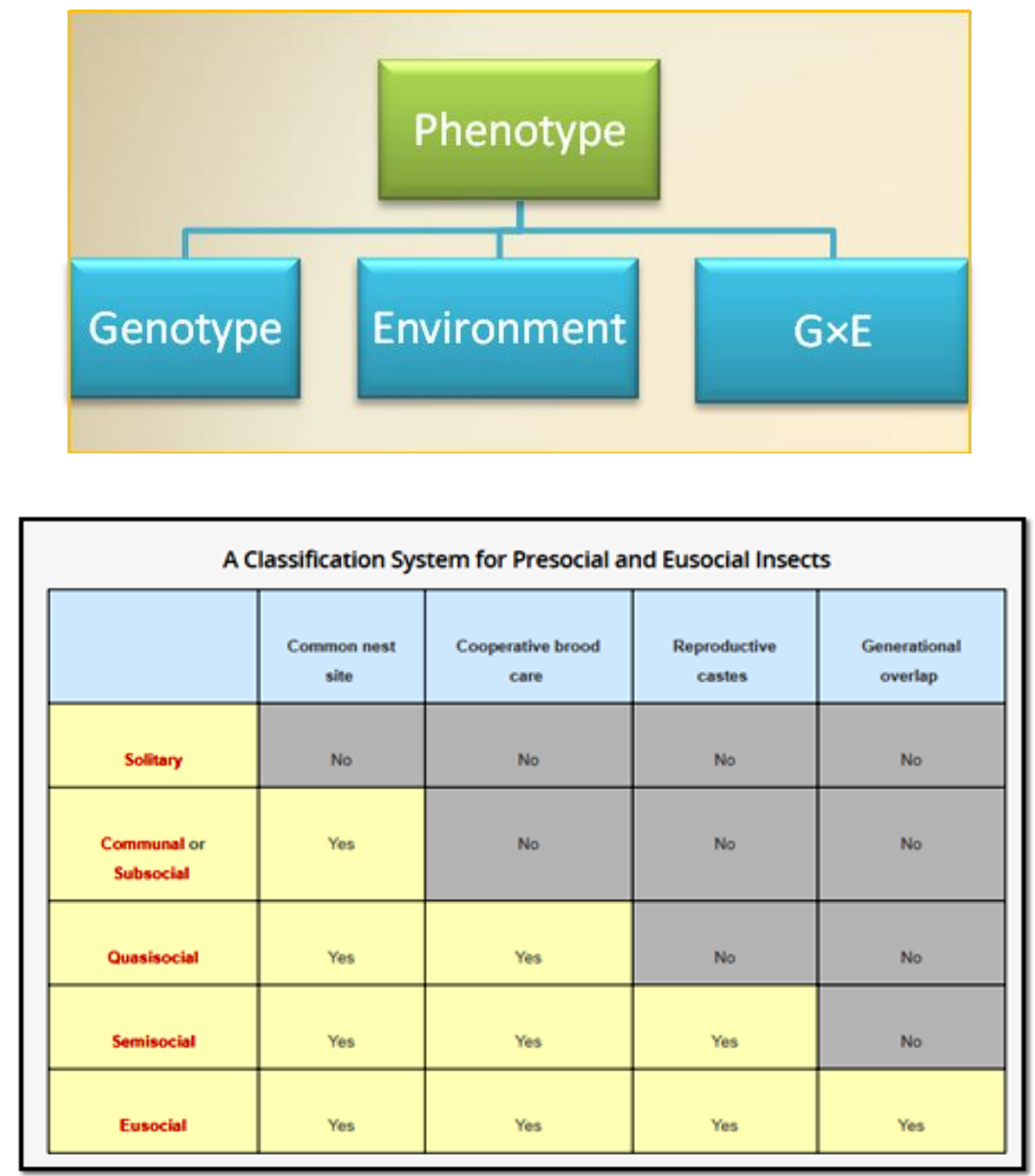

Wilson and Holldobler, 2005

\section{Why not Drosophila melanogaster???}

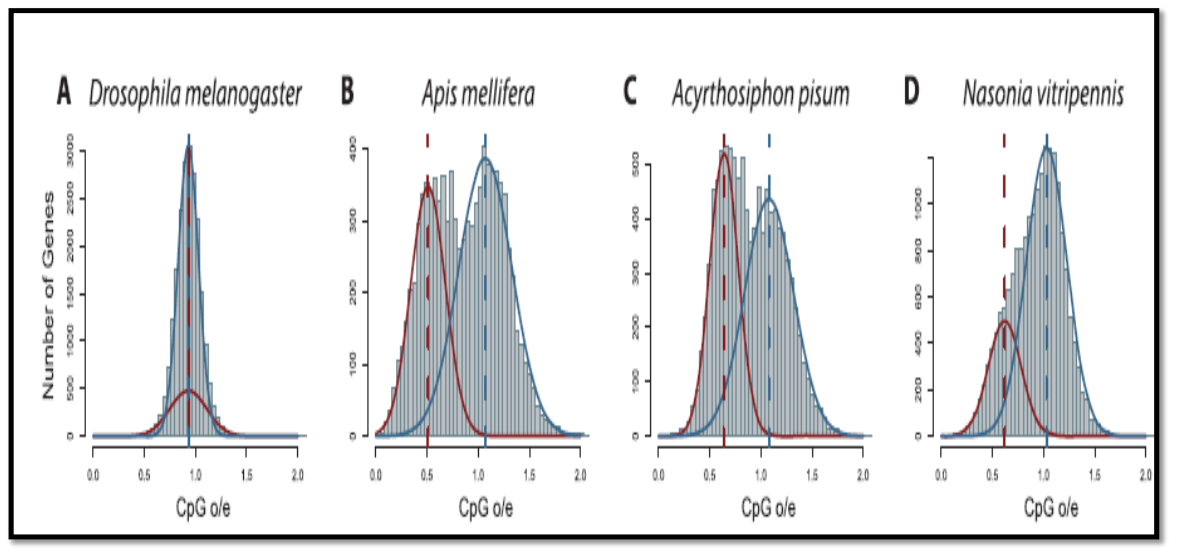

Glastad et al., 2013 


\section{What is DNA methylation?}

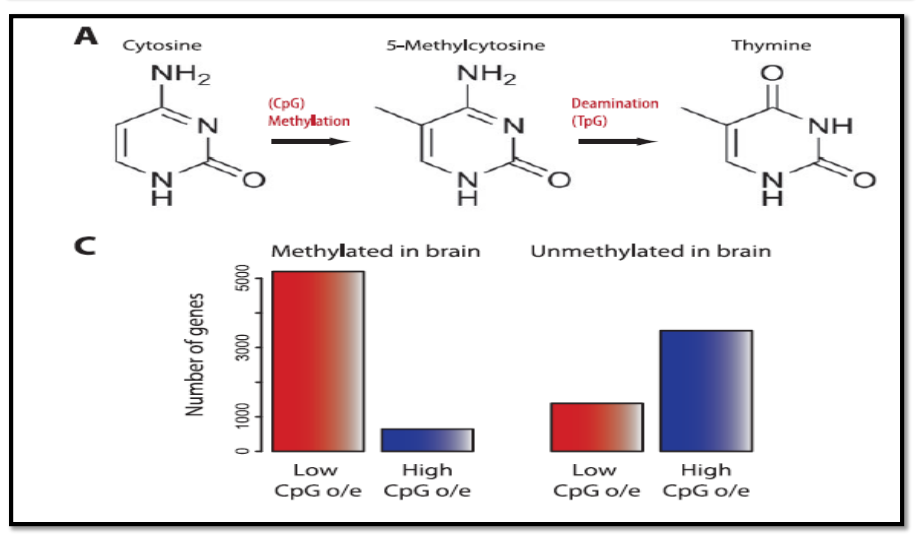

Lyko et al., 2010

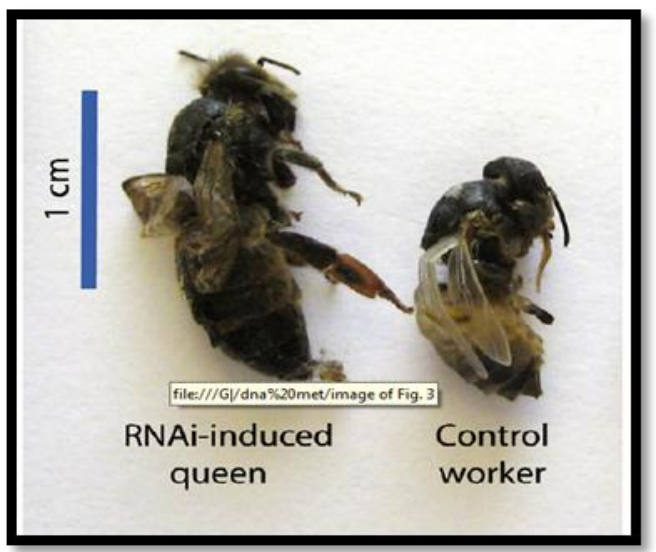

A Drosophilamelanogaster

B Apismellifera

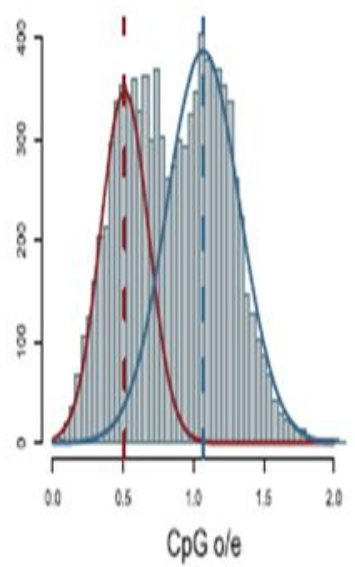

C Acyrthosiphon pisum

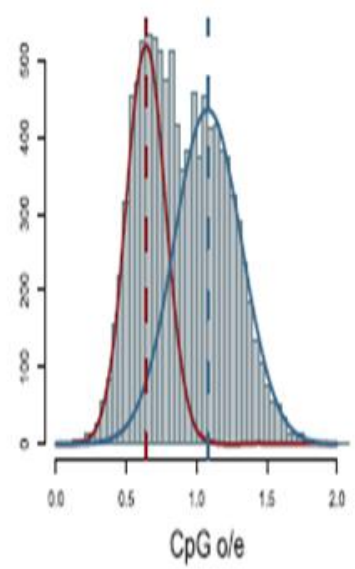

D Nasoniavitipennis

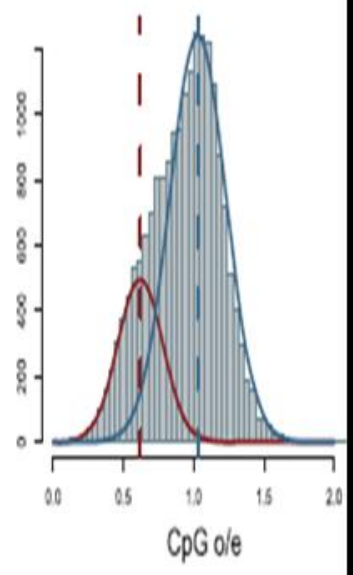



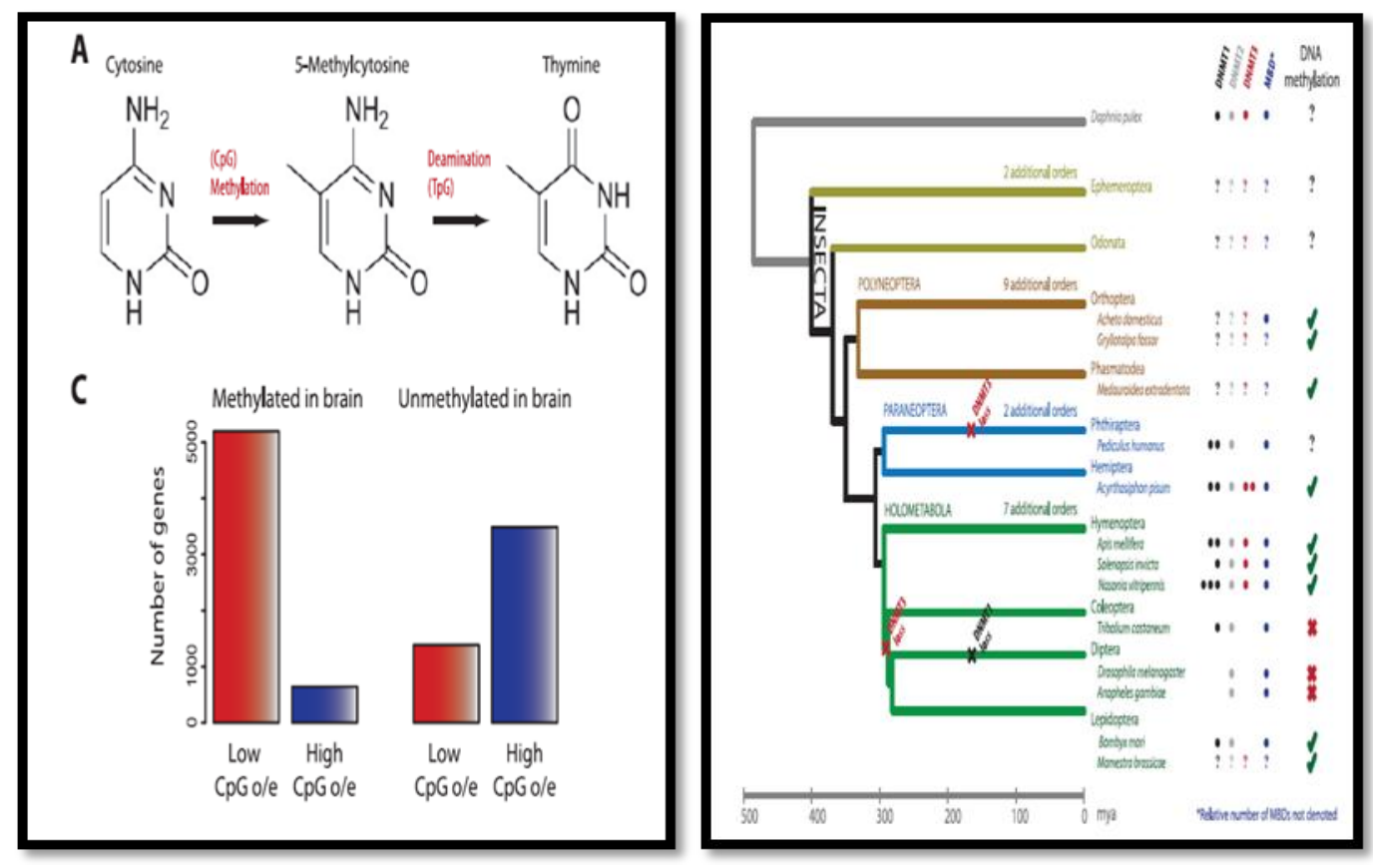

Lyko et al., 2010
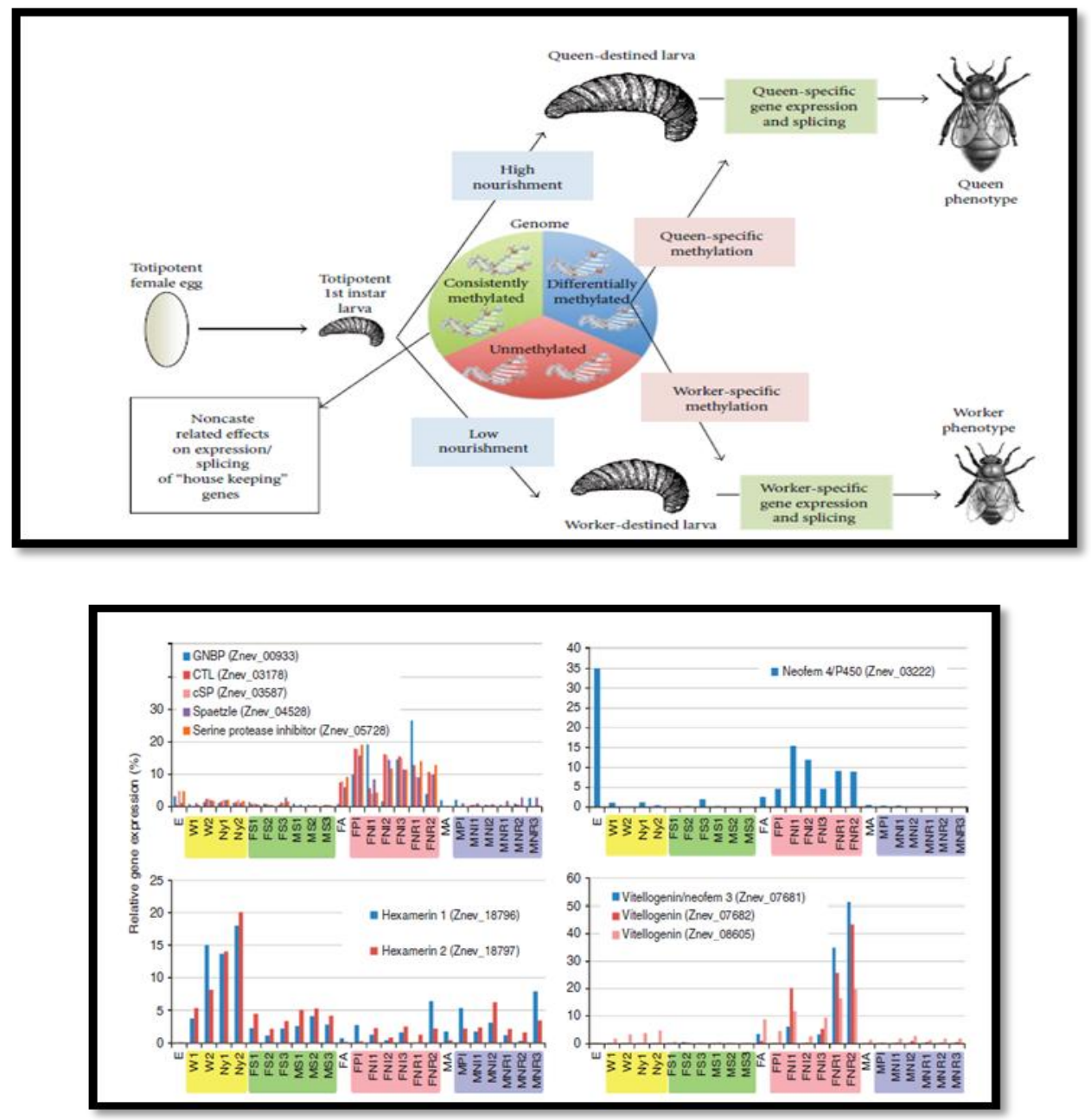


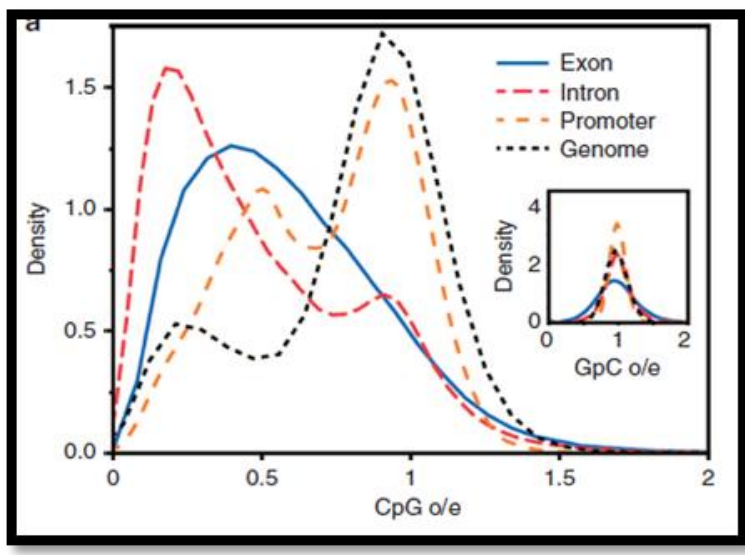

Thus the experimental evidences suggested that the silencing of the DNMT 3 caused the worker destined larva to develop queen like traits in honey bee.

\section{DNA methylation in termites}

Termites are the eusocial insects reported to be independently originated from the hymenopterans. The complex social adaptiveness of termites lead to the development of eusociality in this order (Eggleton et al., 2011). In termites the caste system is also well evolved like other social insects such as honey bees, ants etc. king and queen are the reported termite reproducing castes whereas, workers and soldiers are involved in the non-reproducing activities such as brood care, foraging and defense (Mao et al., 2005: Scharf et al., 2007: Toru and Scharf, 2011). Blattodea, being the monophyletic sister clade of isopteran termites has also suggested the different eusocial evolution than the hymenopterans. The hymenopterans being the holometabolous insects have a specialized pupal instar which is absent in the hemimetabolous termites. Misof et al., (2014) suggested the independent origin of isopteran from hymenoptera. There are also some isoptera specific genes that are reported to be absent in hymenopteran insects. The methylation in genomic DNA was reported to be highest in Zootermopsis nevadensis than in Apis

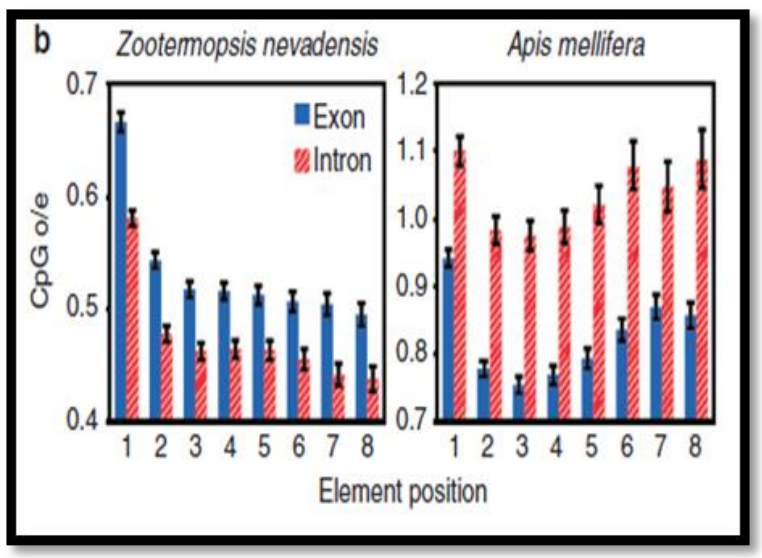

mellifera, C. floridanus (Glastad et al., 2016). The caste and sex specific genes are reported to be differently methylated within different insects. Even though the hymenopterans and isopterans have different ancestral origin, the termites produce some caste specific Hydro carbons, $\mathrm{CHCs}$ which are also involved in the division of labour (Korb and Hartfelder, 2008: Oystaeyen, 2014).

In termites, three groups of proteins involved in the synthesis of CHCs: desaturases (introduction of double bonds), elongases (extension of C-chain length) and CYP4G1 (last step of CHC biosynthesis) (Weil et al., 2009; Dietemann et al., 2003; Dallerac et al., 2000). Apart from this, the chemical communication in insects also involves some of the genes such as odorant receptors (ORs), gustatory receptors (GRs) and ionotropic receptors (IRs).recently the DNA methylation status in termites has be elucidated because, most of the methylation occurs in the Housekeeping genes, that lead to functional specialization through different caste specific gene expression (Terrapon et al., 2014: Joseph and Carlson, 2015). Most of the transcriptions in termites are carried out by the transcription factor Zinc Finger (ZF) proteins. Some of the queen biased $\mathrm{ZF}$ proteins are over expressed in the termite queens indicating the functional DNA methylation. Apart from this, the other two $\mathrm{ZF}$ families such as Bhlh and bZIP are not 
differentially expressed in the termites taxa (Schmitz et al., 2016).

The endocrine genes are also involved in eusociality. The ecdysone synthesis process in termites involve six Halloween genes, out of which only one Halloween gene shade has been reported to be differentially expressed in first nymphal stages and adult termites (Rewitz et al., 2006). Furthermore, the ecdysone kinase gene which converts the activated ecdysone into ecdysone phosphate, for storage (Sonobe et al., 2006). This gene also has been reported to be overexpressed in female adults as compared to nymphs of termites. Apart from this the juvenile hormone binding protein (JHBPs) are involved in the transfer of JHs to the target site of action, thus this genes were also reported to be differentially expressed and thus their methylation was also confirmed (Jindra et al., 2015; Korb, 2015). If the DNA methylation in different insects is to be considered, termites were reported to show higher level of DNA methylation. Different genes have been reported to involve in chemoreception, regulation of female reproductives and mating biology of an organism. If the immunity related genes are taken into consideration, the gram negative bacteria protein binding (GNBPs) are reported to be overexpressed in termites than other social insects. Some termite specific GNBPs such as GNBP 1 and GNBP 2 are reported to be overexpressed. Inspite of living in pathogen rich environment, only 3 antimicrobial peptides (AMPs) such as attacin, diptericin and termiticin are reported to be highly expressed indicating that the pathogens impart major threats to the eusocial insects, but the ways to combat these pathogens is different in diverse taxa of social insects.

Different caste specific, reproductive specific genes such as Juvenile hormone, vitellogenin, biogenic amine, insulin like growth factors are also differentially expressed in different sex and caste of termites (Amdam et al., 2003).

In the figure from Terrapon et al., (2014), the yellow bars indicate worker and nymphs, green bar indicates soldiers, pink bar indicates reproductive females whereas blue bars indicate reproductive males. From the figure, it can be concluded that, the GNBPs are highly expressed in the reproductive females of termites (Schmid- Hempel, 1998). CYP 450 related gene, Neofem 4 are responsible for oxidising endogenous substances and detoxifying the xenobiotics. Among these, the members of CYP 4 and CYP 15 family are reported to be involved in $\mathrm{JH}$ dependent termite worker to soldier differentiation. If the expression of female specific vitellogenin gene is to be considered, the highest expression was observed in the reproductive female caste of termites, apart from this, this gene was also expressed in workers and nymphs indicating some diverse morphological role in termites. Hexamerin otherwise known as storage protein was reported to be of 3 types in insects, one is present throughout the insect, and another 2 are blattodea specific. The later type of hexamerin is responsible for the soldier development in termites by acting as the regulator of $\mathrm{JH}$ availability.

Furthermore, the Odorant Receptor genes (ORs) are reported to be expressed less in Zootermopsis nevadensis than the social Hymenopterans. One possible cause may be the long range foraging behaviour of the honey bee, which is limited to the single wood log in case of termites (Bulmer, 2010).

From the above graph, it can be concluded that the DNA methylation occurs mostly in the genomic region i.e. mostly in the exonic and intron regions. But if the European honey bee, Apis mellifera is taken into consideration, 
it was reported with the exactly opposite trend as the DNA methylation occurs mostly in the intron specific region. Furthermore, alternative splicing events goes on increasing, the $\mathrm{CpG}$ o/e goes on decreasing, thus indicating that alternatively spliced genes are the preferential target site for the DNA methylation.

Thus DNA methylation has been an important regulating factor in the regulation of sociality, which is controlled by environmental factors. Thus the knowledge of this DNA methylation can be used for up-regulation and downregulation of various genes related to the methylation and various pests can be controlled and the beneficial insects can thus be effectively manipulated by using this approach. But still there is a need of complete genome sequence of the target insect to be controlled.

\section{References}

Amdam, G. V., Norberg, K., Hagen, A. and Omholt, S. W. 2003. Social exploitation of vitellogenin. Proceedings of National Academy of Sciences, USA. 100: 17991802.

Bossdorf, O., Richards, C.L. and Pigliucci, M., 2008. Epigenetics for ecologists. Ecology Letters. 11: 106-115.

Bulmer, M. S. 2010. Evolution of immune proteins in insects. eLS.

Dallerac, R., Labeur, C., Jallon, J.M., Knipple, D.C., Roelofs, W.L. and Wicker-Thomas, C. 2000. A delta 9 desaturase gene with a different substrate specificity is responsible for the cuticular diene hydrocarbon polymorphism in Drosophila melanogaster. Proceedings of the National Academy of Sciences. 97, 9449\{9454.

Dietemann, V., Peeters, C., Liebig, J., Thivet, V. and Holldobler, B. 2003. Cuticular hydrocarbons mediate discrimination of reproductives and nonreproductives in the ant Myrmecia gulosa. Proceedings of the National Academy of Sciences. 100, $10341\{10346$.

Eggleton, P. 2011. An introduction to termites: biology, taxonomy and functional morphology. In Biology of Termites: A Modern Synthesis (Bignell, D.E., Roisin, Y. and Lo, N., eds), pp. 127. Springer, London.

Glastad, K. M., Gokhale, K., Liebig, J. and Goodisman, M. A. D. 2016. The casteand sex-specific DNA methylome of the termite Zootermopsis nevadensis. Scientific Reports. 6, 37110

Glastad, K. M., Hunt, B. G., Yi, S. V. and Goodisman, M. A. D. 2011. DNA methylation in insects: on the brink of the epigenomic era. Insect Molecular Biology. 20: 553-565.

Glastad, K.M., Chau, L.M. and Goodisman, M.A.D., 2015. Epigenetics in Social Insects. In: Zayed, A., Kent, C.F. (Eds.), Genomics, Physiology and Behaviour of Social Insects Vol. 48. London, Academic Press, pp. 227-270.

Glastad, K.M., Hunt, B.G. and Goodisman, M.A.D., 2013. Evidence of a conserved functional role for DNA methylation in termites.. Insect Molecular Biology. 22: 143-154.

Glastad, K.M., Hunt, B.G., Yi, S.V. and Goodisman, M.A.D., 2011. DNA methylation in insects: on the brink of the epigenomic era. Insect Molecular Biology. 20: 553-565.

Glastad, K.M., Hunt, B.G., Yi, S.V. and Goodisman, M.A.D., 2014. Epigenetic inheritance and genome regulation: is DNA methylation linked to ploidy in haplodiploid insects? Proc. R. Soc. Lond. B 281, Art No.: 20140411.

Jindra, M., Belles, X. and Shinoda, T. 2015. Molecular basis of juvenile hormone 
signaling. Current Opinion in Insect Science.11: 39-46.

Joseph, R. M. and Carlson, J. R. 2015. Drosophila Chemoreceptors: A Molecular Interface Between the Chemical World and the Brain. Trends in Genetics. 31: 683- 695.

Korb, J. 2014. Juvenile Hormone: A Central Regulator of Termite Caste Polyphenism. In Kent, A. Z. and C. F. (ed.) Advances in Insect Physiology, vol. 48 of Genomics, Physiology and Behaviour of Social Insects, 131-161 (Academic Press, 2015). DOI: 10.1016/bs.aiip.2014.12.004.

Korb, J. and Hartfelder, K. 2008. Life history and development - a framework for understanding developmental plasticity in lower termites. Biological Reviews. 83: 295-313.

Lan, J., Hua, S., He, X.N. and Zhang, Y., 2010. DNA methyltransferases and methyl-binding proteins of mammals. Acta Biochimica et Biophysica Sinica. 42: 243-252.

Law, J.A. and Jacobsen, S.E., 2010. Establishing, maintaining and modifying DNA methylation patterns in plants and animals. Nature Reviews Genetics. 11: 204-220.

Lyko, F., Foret, S., Kucharski, R., Wolf, S., Falkenhayn, C., Maleszka, R., 2010. The honey bee epigenomes: differential methylation of brain DNA in queens and workers. PLoS Biol. 8, e10000506.

Maleszka, R. 2012. Elucidating the path from genotype to behaviour in honey bees: insights from epigenomics. In: Eisenhardt D, Galizia G, Giurfa M editors. Honeybee Neurobiology and Behavior: A Tribute to Randolf Menzel. Amsterdam: Springer Publisher. pp. 373-86.

Mao, L., Henderson, G., Liu, Y. and Laine, R.A. 2005. Formosan subterranean termite (Isoptera: Rhinotermitidae) soldiers regulate juvenile hormone levels and caste differentiation in workers. Annals of Entomological Society of America. 98: 340-345.

Miklos GL, Maleszka R. 2000. Deus ex genomix. Nature Neuroscience. 3: 424425.

Misof, B. et al., 2014. Phylogenomics resolves the timing and pattern of insect evolution. Science. 346: 763-767.

Nanney, D.L., 1958. Epigenetic control systems. Proceedings of National Academy of Sciences. U.S.A. 44: 712717.

Oystaeyen, A. V. et al., 2014.Conserved Class of Queen Pheromones Stops Social Insect Workers from Reproducing. Science. 343: 287-290.

Pigliucci, M., 2001. Phenotypic Plasticity: Beyond Nature and Nurture. Johns Hopkins University Press, Baltimore, MD.

Rewitz, K. F., Rybczynski, R., Warren, J. T. and Gilbert, L. I. 2006. The Halloween genes code for cytochrome P450 enzymes mediating synthesis of the insect moulting hormone. Biochemical Society Transactions. 34: 1256-1260.

Richards, E.J. 2006. Opinion-inherited epigenetic variation-revisiting soft inheritance. Nature Review Genetics. 7: 395-401.

Scharf, M.E., Buckspan, C.E., Grzymala, T.L. and Zhou, X. 2007. Regulation of polyphenic caste differentiation in the termite Reticulitermes flavipes by interaction of intrinsic and extrinsic factors. Journal of Experimental Biology. 210: 4390-4398.

Schmid-Hempel, P. Parasites in Social Insects (Princeton Univ. Press, 1998).

Schmitz, J. F., Zimmer, F. and BornbergBauer, E. 2016. Mechanisms of transcription factor evolution in Metazoa. Nucleic Acids Research. 44: 6287- 6297 (2016). 
Sonobe, H. et al., 2006. Purification, Kinetic Characterization, and Molecular Cloning of a Novel Enzyme, Ecdysteroid 22-Kinase. Journal of Biological Chemistry. 281: 2951329524.

Terrapon, N. et al., 2014. Molecular traces of alternative social organization in a termite genome. Nature Communications. 5: 3636.

Toru, M. and Scharf, M.E. 2011. Molecular basis underlying caste differentiation in termites. In Biology of Termites: A Modern Synthesis (Bignell, D.E., Roisin, Y. and Lo, N., eds), pp. 211253. Springer, London.

Waddington, C.H., 1942. The epigenotype. Endeavour 1, 18-20, Reprinted in International Journal of Epidemiology 2012. 41:10-13.
Weil, T., Hoffmann, K., Kroiss, J., Strohm, E \& Korb, J. 2009. Scent of a queen cuticular hydrocarbons specific for female reproductives in lower termites. Naturwis senschaften. 96: 315- 319.

Weiner, S.A., Toth, A.L., 2012. Epigenetics in social insects: a new direction for understanding the evolution of castes. Genetic Research International. Article ID 609810.

Wilson, E.O. 1971. The Insect Societies, The Belknap Press of Harvard University Press, Cambridge, Mass, USA, 2nd edition.

Wilson, E.O. and Holldobler, B. 2005. The rise of the ants: a phylogenetic and ecological explanation. Proceedings of the National Academy of Sciences. 102 (21): 7411-7414.

\section{How to cite this article:}

Ipsita Samal. 2018. Epigenetic Control of Sociality through DNA Methylation. Int.J.Curr.Microbiol.App.Sci. 7(10): 2751-2762. doi: https://doi.org/10.20546/ijcmas.2018.710.320 